\title{
Stratus-Fog Formation and Dissipation: A 6-Day Case Study
}

\author{
Jean-Charles Dupont • Martial Haeffelin • \\ Alain Protat • Dominique Bouniol • Neda Boyouk • \\ Yohann Morille
}

Received: 31 October 2010 / Accepted: 11 January 2012 / Published online: 2 March 2012

(C) The Author(s) 2012. This article is published with open access at Springerlink.com

\begin{abstract}
A suite of active and passive remote sensing instruments and in-situ sensors deployed at the SIRTA Observatory (Instrumented Site for Atmospheric Remote Sensing Research), near Paris, France, for a period of six months (October 2006-March 2007) document simultaneously radiative, microphysical and dynamic processes driving the continental-fog life cycle. The study focuses on a 6-day period between 23 and 29 December 2006 characterized by several stratus-cloud lowering and lifting events and almost $18 \mathrm{~h}$ of visibility below $1 \mathrm{~km}$. Conceptual models and different possible scenarios are presented here to explain the formation, the development and the dissipation phases of three major stratus-fog events and to quantify the impact of each driving process. For example, slowly evolving large-scale conditions characterized by a slow continuous cloud-base lowering, followed by a rapid transient period conductive to fog formation and dissipation, are observed for cases 1 and 3. During this stable period, continuous cloud-top radiative cooling $\left(\approx-160 \mathrm{Wm}^{-2}\right)$ induces a progressive and slow lowering of the cloud base: larger droplets at cloud top (cloud reflectivity approximately equals to $-20 \mathrm{dBZ}$ ) induce slow droplet fall to and beyond cloud base (Doppler velocity $\approx-0.1 \mathrm{~m} \mathrm{~s}^{-1}$ ), cooling the sub-cloud layer by evaporation and lowering the saturation level to $100 \mathrm{~m}$ (case 1) or to the surface (cases 2 and 3). Suddenly, a significant increase in Doppler velocity magnitude $\approx-0.6 \mathrm{~m} \mathrm{~s}^{-1}$ and of turbulent kinetic energy dissipation rate around $10^{-3} \mathrm{~m}^{2} \mathrm{~s}^{-3}$ occurs at cloud base (case 1). These larger cloud
\end{abstract}

J.-C. Dupont $(\otimes) \cdot$ M. Haeffelin

Institut Pierre Simon Laplace, Ecole Polytechnique, Palaiseau, France

e-mail: jean-charles.dupont@ipsl.polytechnique.fr

A. Protat

Laboratoire Atmospheres Milieux, Observations Spatiales, Guyancourt, France

D. Bouniol

Groupe d'étude de l'Atmosphère Metéorologique/Centre National de la Recherche en Météorologie, CNRS/Météo-France, Toulouse, France

N. Boyouk · Y. Morille

Laboratoire de Météorologie Dynamique, Institut Pierre Simon Laplace, Ecole Polytechnique, Palaiseau, France 
droplets reach the surface leading to fog formation over $1.5 \mathrm{~h}$. The Doppler velocity continues to increase over the entire cloud depth with a maximum value of around $-1 \mathrm{~m} \mathrm{~s}^{-1}$ due to the collection of fog droplets by the drizzle drops with high collection efficiency. As particles become larger, they fall to the ground and lead to fog dissipation. Hence, falling particles play a major role in both the formation and also in the dissipation of the fog. These roles co-exist and the balance is driven by the characteristics of the falling particles, such as the concentration of drizzle drops, the size distribution of drizzle drops compared to fog droplets, Doppler velocity and thermodynamic state close to the surface.

Keywords Fog life cycle $\cdot$ Fog observations $\cdot$ In-cloud processes $\cdot$ Stratus cloud

\section{Introduction}

The most studied and therefore well-described fog type is that associated with radiative cooling, and which can be divided into: radiation fog, high inversion fog, and advection-radiation fog. Radiation fog usually forms near the surface under clear skies in stagnant air in association with anticyclonic conditions (Gultepe et al. 2007). The high inversion fog usually forms in valleys within a deep moist layer capped by a strong inversion (Holets and Swanson 1981). The inversion results from prolonged radiative cooling and subsidence associated with a persistent anticyclone. This type of fog is common during winter in the central valley of California (Underwood et al. 2004). Advection-radiation fog is a coastal phenomenon and results from the radiative cooling of moist air that has been advected over land from the ocean or from any large water body during the previous daylight hours (Ryznar 1977). These different types of fog have an impact on traffic safety and air quality due to the potential rapid change in visibility range down to $50 \mathrm{~m}$ (Elias et al. 2009). During recent decades, their impact has significantly increased related to the increase in air, marine, rail and road traffic. To reduce the hazards in transportation activities, more accurate forecasting and nowcasting of fog events are needed.

The mechanisms of fog formation, development and dissipation are very complex and have been extensively studied with a series of numerical simulations and comprehensive observational programs including in-situ measurements (Gultepe et al. 2007). From the numerical modelling point of view, models usually lack accuracy due to the horizontal (Pagowski et al. 2004) and vertical (Tardif 2007) resolutions, and physical parametrizations (Musson-Genon 1987; Gultepe et al. 2007). One-dimensional models are computationally more economical and are useful in some situations (Bergot et al. 2005), whereas detailed three-dimensional models are needed to better understand the physical processes related to turbulence, radiative transfer in the atmosphere, and aerosol/droplet microphysical properties (Müller et al. 2007). To evaluate the forecasting of the fog life cycle, and also to document the involved physical processes, several field campaigns have been performed over the last few decades (Pilié et al. 1975; Fuzzi et al. 1992; Bergot et al. 2008). However, progress in the operational forecasting of fog has been limited due to the numerous factors spanning spatial and temporal scales that influence fog.

An investigation of stratus-lowering processes that lead to the formation of fog was carried out by Koracin et al. (2000) using a one-dimensional model and observations. Their results show that radiative cooling and large-scale subsidence are an important factor in fog formation. In fact, the radiative cooling at cloud top is the primary mechanism for cooling and mixing the cloud-topped marine layer and the subsidence acts to strengthen the inversion above the cloud top and forces lowering of the cloud. In addition, the one-dimensional 
model indicates that the sensible and latent heat fluxes are of secondary importance. Oliver et al. (1978) studied in detail the interactions between radiative and turbulence processes and found that radiative cooling at fog top is an important process in the fog life cycle. Telford and Chai (1984) have shown that microphysical processes and entrainment are the two major mechanisms that drive the lowering of stratus to fog whereas Tag and Peak (1996) showed that the presence of a sufficiently shallow stratus cloud capped by a strong inversion and moist sub-cloud layer are important factors.

However, the stratus lowering has not been extensively discussed in the literature, particularly for continental surfaces. Thus, in our study, we analyze the relative impact of each mechanism (cloud-top radiative cooling, surface thermodynamic effects, cloud/drizzle microphysics) during the stratus-fog life cycle over a continental site.

ParisFog was a 6-month field measurement campaign dedicated to the collection of a comprehensive dataset suitable for the study of multiple processes (thermodynamical, radiative, dynamical, microphysical) and their respective importance in driving fog formation, development and dissipation (Bergot et al. 2008; Haeffelin et al. 2010). The various processes involved in the fog life cycle may be determined and analyzed through a suite of active and passive remote sensing instruments and in-situ sensors deployed at the SIRTA Observatory (Haeffelin et al. 2005).

We focus on a 6-day period characterized by persistent low stratus cloud producing three major fog periods and a total of $18 \mathrm{~h}$ with a visibility lower than $1 \mathrm{~km}$. Section 2 describes the instruments deployed in routine mode at SIRTA Observatory and the specific measurements dedicated to documenting fog processes during the ParisFog campaign. Section 3 analyzes the different processes involved in the lowering and lifting of the stratus cloud for three case studies, while concluding remarks are given in Sect. 4.

\section{Observational Dataset}

\subsection{The SIRTA Site and the ParisFog Campaign}

The SIRTA (Site Instrumental de Recherches par Télédétection Atmosphérique) is a French National Observatory dedicated to the monitoring of clouds and aerosols occurring in the troposphere, the dynamics and thermodynamics of the boundary layer, and the turbulent and organized transport of water and energy near the surface. The SIRTA observatory is a mid-latitude site $\left(48.7^{\circ} \mathrm{N}, 2.2^{\circ} \mathrm{E}\right)$ located in a semi-urban area, on the Saclay plateau $25 \mathrm{~km}$ south of Paris, and houses active and passive remote sensing instruments since 2002 (Haeffelin et al. 2005). The SIRTA strategy is, on the one hand, to monitor continuously an atmospheric column using a core ensemble of instruments and, on the other hand, to coordinate field campaigns in order to address special scientific questions, such as processes related to water vapour, the ultraviolet radiation or the aerosol physics and chemistry.

A suite of active and passive remote sensing instruments and in-situ sensors were deployed at the SIRTA site for a 6-month period (October 2006-March 2007). During this field experiment called ParisFog (Bergot et al. 2008), profiles of wind speed, turbulence, microphysical and radiative properties, as well as temperature, humidity, aerosol and fog droplet-size distribution and chemical composition in the surface layer, were monitored (Haeffelin et al. 2010). Almost 100 fog and near-fog events were documented in order to provide a dataset well-suited to study the dynamical, radiative and microphysical processes involved in the fog life cycle (Elias et al. 2009; Boyouk et al. 2011). 
Table 1 Active and passive remote sensing instruments and the in-situ sensors deployed at the SIRTA site for the ParisFog campaign and used for this study

\begin{tabular}{|c|c|c|c|c|}
\hline $\begin{array}{l}\text { Type of the } \\
\text { instruments }\end{array}$ & Name & Measurements & Sampling & Uncertainty \\
\hline \multirow[t]{2}{*}{$\begin{array}{l}\text { Active remote } \\
\text { sensing }\end{array}$} & $\begin{array}{l}\text { Vaisala CT25K } \\
\text { ceilometer }(905 \mathrm{~nm})\end{array}$ & $\mathrm{CBH}$ & $30 s$ & $15 \mathrm{~m}$ \\
\hline & $\begin{array}{l}\text { RASTA } \\
\text { Doppler } \\
\text { cloud radar } \\
(95 \mathrm{GHz})\end{array}$ & $\begin{array}{l}\text { CTH In-cloud } \\
\text { reflectivity }(\mathrm{dBz}) \text {, } \\
\text { Doppler velocity } \\
\left(\mathrm{m} \mathrm{s}^{-1}\right) \text { and TKE } \\
\text { rate }\left(\mathrm{m}^{2} \mathrm{~s}^{-3}\right)\end{array}$ & $5 s$ & $60 \mathrm{~m}$ \\
\hline $\begin{array}{l}\text { Passive remote } \\
\text { sensing }\end{array}$ & $\begin{array}{l}\text { Surface pyrgeometer } \\
\text { and pyranometer }\end{array}$ & $\begin{array}{l}\text { Shortwave and } \\
\text { longwave } \\
\text { downwelling and } \\
\text { upwelling fluxes } \\
\left(\mathrm{W} \mathrm{m}^{-2}\right)\end{array}$ & $1 \mathrm{~min}$ & $\begin{array}{l}4 \mathrm{~W} \mathrm{~m}^{-2} \text { for } \\
\text { longwave } 5 \mathrm{~W} \mathrm{~m}^{-2} \\
\text { for shortwave }\end{array}$ \\
\hline \multirow[t]{5}{*}{ In-situ sensors } & $\begin{array}{l}\text { Degreanne DF20+ } \\
\text { visibilimeter }\end{array}$ & $\begin{array}{l}\text { Horizontal visibility } \\
\quad(\mathrm{km})\end{array}$ & $1 \mathrm{~min}$ & $\pm 15 \%$ \\
\hline & $\begin{array}{l}\text { Temperature and } \\
\text { humidity sensors } \\
\text { located at } 1,2,5,10 \\
\text { and } 30 \mathrm{~m}\end{array}$ & $\begin{array}{l}\text { Temperature and } \\
\text { humidity at five } \\
\text { levels above the } \\
\text { ground }\end{array}$ & $1 \mathrm{~min}$ & $\begin{array}{l}0.2^{\circ} \mathrm{C} \text { for temperature } \\
2 \% \text { for relative } \\
\text { humidity }\end{array}$ \\
\hline & $\begin{array}{l}\text { Young sonic } \\
\text { anemometers and } \\
\mathrm{KH} 20 \text { sensor } \\
\text { located at } 10 \mathrm{~m}\end{array}$ & $\begin{array}{l}\text { Turbulent kinetic } \\
\text { energy, latent and } \\
\text { sensible heat fluxes }\end{array}$ & $5 \mathrm{~min}$ & - \\
\hline & RS90 radiosondes & $\begin{array}{l}\text { Pressure, temperature, } \\
\text { humidity, wind } \\
\text { speed and direction } \\
(0-20 \mathrm{~km})\end{array}$ & $\begin{array}{l}0000 \text { and } \\
1200 \\
\text { UTC }\end{array}$ & $\begin{array}{l}0.2^{\circ} \mathrm{C} \text { for temperature } \\
2 \% \text { for relative } \\
\text { humidity }\end{array}$ \\
\hline & $\begin{array}{l}\text { Tapered element } \\
\text { oscillating } \\
\text { microbalance }\end{array}$ & $\begin{array}{l}\text { PM2.5 mass } \\
\text { concentration } \\
\left(\mu \mathrm{gm}^{-3}\right)\end{array}$ & $10 \min$ & $\pm 1.5 \mu \mathrm{g} \mathrm{m}^{-3}$ \\
\hline
\end{tabular}

\subsection{Instruments}

Table 1 describes the active and passive remote sensing instruments and the in-situ sensors deployed at the SIRTA site for the ParisFog campaign and used in this study. Variables derived from each instrument and the raw sampling resolutions are also given.

The cloud-base height $(\mathrm{CBH})$ and the cloud-top height are derived from the CT25K ceilometer backscatter signal and the RASTA (Radar Aéroporté et Sol pour la Télédétection des propriétés nuAgeuses, Protat et al. 2004) cloud radar, respectively. The ceilometer and radar blind zones are equal to 60 and $180 \mathrm{~m}$, with vertical resolutions of 15 and $60 \mathrm{~m}$, respectively. This zone corresponds to the altitude that lacks information on lidar backscatter or radar reflectivity and Doppler velocity. In this study, all altitudes are considered above the ground level (denoted a.g.l.). In-cloud reflectivity, mean Doppler velocity and the turbulent kinetic energy (TKE) dissipation rate $(\varepsilon)$ are derived from the RASTA cloud-radar measurements. This radar operates in a vertically-pointing mode and at a frequency of $95 \mathrm{GHz}$ suited for the characterization of microphysical properties of fog and stratus above $180 \mathrm{~m}$ height. The sensitivity of this radar is about $-52 \mathrm{dBZ}$ at $1 \mathrm{~km}$ for a temporal resolution of $1 \mathrm{~s}$ used for this study, allowing for most fog and all stratus events above $180 \mathrm{~m}$ to be detected. The Doppler velocity measurement is the sum of vertical air motions and terminal fall speed of the droplets. 
It can be reasonably assumed that it is a good proxy for vertical air motions in fog, given that fog droplets are very small and therefore fall at a slow terminal speed when compared to the vertical air motions. The TKE dissipation rate is derived from the temporal variance of the mean Doppler velocity (Bouniol et al. 2003). The method assumes that the length scales of the turbulent eddies observed by the radar are in the inertial subrange of the turbulence spectrum and that turbulence, rather than fluctuations in particle terminal velocities, is the dominant contribution to this variance for the time scale of interest (O'Connor et al. 2005; Shupe et al. 2007).

The SIRTA radiative flux station (Haeffelin et al. 2005) is a Baseline Surface Radiation Network station (Ohmura et al. 1998) and shortwave and longwave downwelling irradiances are used to derive the surface radiative budget. An average surface albedo of $0.22 \pm 0.02$ and an average ground emissivity of $0.98 \pm 0.01$ are derived from the $30-\mathrm{m}$ mast upwards and downwards measurements. A Degreanne DF20+ visibilimeter was operated near the ground (4-m height). The instrument provided horizontal visibility range and particle extinction at $550 \mathrm{~nm}$, with a 10-25\% uncertainty. The vertical profiles of thermodynamic variables are documented using a combined analysis of the output of in-situ sensors. The temperature and humidity non-aspirated sensors located between 1 and $30 \mathrm{~m}$ height on an instrumented mast provided continuous measurements (1-min temporal resolution). Measurements were extended vertically by radiosonde profiles performed routinely at 0000 and 1200 UTC 15 $\mathrm{km}$ west of SIRTA as part of the Météo-France national network.

\subsection{Overview of the 6-Day Period}

Figure 1 presents the temporal evolution of reflectivity profiles during the 6-day stratus cloud event observed by the RASTA cloud radar. The $\mathrm{CBH}$ is derived from the ceilometer using the Morille et al. (2007) algorithm, while the cloud-top height (CTH) corresponds to the maximum altitude where the radar signal was detected above the noise level. It may not correspond exactly to the true cloud top, but it can be considered as a good proxy for cloud top. The stratus cloud formed on 23 December at 1200 UTC and dissipated on 29 December at 0000 UTC. During this 6-day period the $\mathrm{CBH}$ and $\mathrm{CTH}$ were observed between zero and $400 \mathrm{~m}$ and between 300 and $880 \mathrm{~m}$, respectively. The mean $\mathrm{CBH}$ and $\mathrm{CTH}$ over the period under study are 150 and $550 \mathrm{~m}$, respectively. The minimum $\mathrm{CBH}$ measured by the ceilometer is 60 and $180 \mathrm{~m}$ for the radar (the first useful range gate of these instruments).

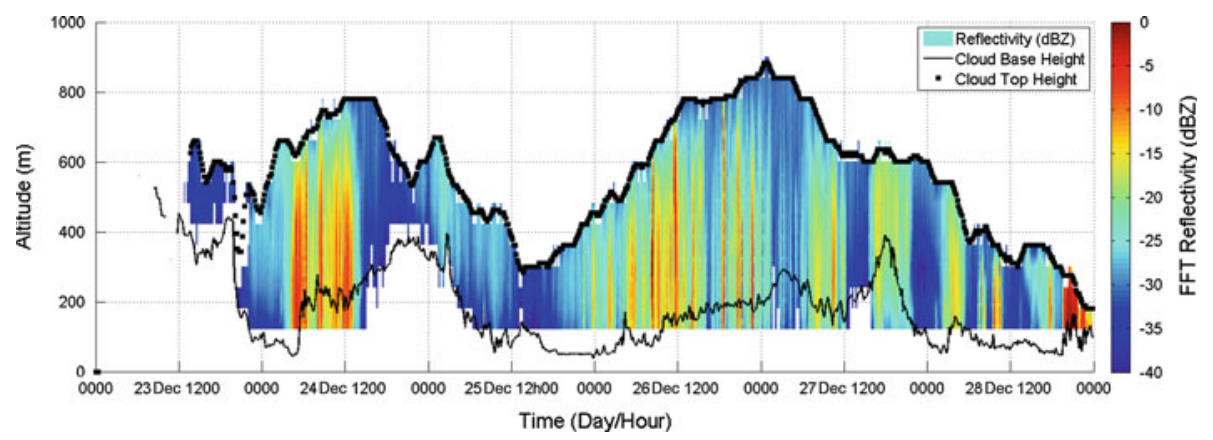

Fig. 1 Radar reflectivity, cloud base and cloud-top altitude between 23 and 29 December 2009. The colour bar corresponds to the fast Fourier transform (FFT) reflectivity derived from the RASTA radar, the thin black solid line to the $\mathrm{CBH}$ and the black square marker to the cloud-top height during the 6-day period 
The backscatter ceilometer signal is proportional to the second power of the droplet diameters and the radar reflectivity to the sixth power. Hence, the largest droplets with a low concentration are likely to be detected by the radar and not detected by the ceilometer. It corresponds to times where the ceilometer cloud base is higher than the radar cloud base in our case study (i.e. 24 December at 1200 UTC and 26 December at 1600 UTC). The period of interest is characterized by a 6-day anticyclonic period, with a near-constant surface pressure between 1,012 and $1,016 \mathrm{hPa}$. We assume that the influence of the mesoscale dynamical processes is limited and does not modify significantly the much faster in-cloud and surface processes.

Table 2 presents the near-surface and the in-cloud properties observed during the fog, near-fog and clear events characterizing the 6-day low stratus period; fog events correspond to a horizontal visibility (noted vis) lower than $1 \mathrm{~km}$, the near-fog event to $1 \mathrm{~km}<v i s<5 \mathrm{~km}$ and clear event to vis $>5 \mathrm{~km}$. We consider that we have a low visibility event if the duration for vis $<1,000 \mathrm{~m}$ is greater than $50 \mathrm{~min}$ within $60 \mathrm{~min}$ of measurement. In fact, the Tardif and Rasmussen (2007) methodology has been used with the proper adjustment of the constants to account for the availability of observations at higher frequency. The temporal coverage, during this 6-day period, for the fog, the near-fog and the clear events is 12,53 and $25 \%$, respectively, corresponding to an average visibility of 514, 3268, 6551 $\mathrm{m}$ for the three types of events. Three main fog events are identified during the life cycle of the stratus: 24 December from 0410 to 0530, 25 December from 1910 UTC to 26 December at 0320 UTC and 28 December from 0200 to $1000 \mathrm{UTC}$. The average air temperature for the fog events is $-1.3^{\circ} \mathrm{C}$ i.e almost $2{ }^{\circ} \mathrm{C}$ lower than the non-fog events. During this 6-day period, the fog events occur at nighttime, which corresponded to cold periods with a very high relative humidity: about $100 \%$ for the fog period and $91 \%$ for the clear periods. The 10 -m horizontal wind speed is

Table 2 Average near-surface and in-cloud properties for the fog, near-fog and clear events calculated during the 6-day period

\begin{tabular}{|c|c|c|c|}
\hline & Fog (i.e. $v i s<1 \mathrm{~km}$ ) & Near-fog (i.e. $1 \mathrm{~km}<$ vis $<5 \mathrm{~km}$ ) & Clear (i.e. vis $>5 \mathrm{~km}$ ) \\
\hline Duration & $17 \mathrm{~h} 40 \mathrm{~min}$ & $75 \mathrm{~h} 30 \mathrm{~min}$ & $50 \mathrm{~h} 50 \mathrm{~min}$ \\
\hline \multicolumn{4}{|l|}{ Near surface properties } \\
\hline 2-m temperature $\left({ }^{\circ} \mathrm{C}\right)$ & -1.3 & 0.2 & 0.5 \\
\hline $\begin{array}{l}\text { 2-m relative } \\
\text { humidity }(\%)\end{array}$ & 100 & 95.5 & 91.4 \\
\hline $10-\mathrm{m}$ wind speed $\left(\mathrm{m} \mathrm{s}^{-1}\right)$ & 1.6 & 1.4 & 1.8 \\
\hline 10-m wind direction $\left({ }^{\circ}\right)$ & 116 & 118 & 156 \\
\hline 10-m TKE $\left(\mathrm{m}^{2} \mathrm{~s}^{-2}\right)$ & 0.5 & 0.6 & 0.7 \\
\hline Horizontal visibility (m) & 514 & 3,268 & 6,552 \\
\hline $\begin{array}{l}\text { PM2.5 mass concentration } \\
\left(\mu \mathrm{g} \mathrm{m}^{-3}\right) \\
\text { In-cloud properties }\end{array}$ & 12 & 22 & 24 \\
\hline Cloud-base altitude (m a.g.l.) & $<60$ & 158 & 192 \\
\hline Cloud-top altitude (m a.g.1.) & 250 & 512 & 620 \\
\hline Average reflectivity (dBZ) & -23.0 & -28.1 & -25.5 \\
\hline $\begin{array}{l}\text { Average Doppler } \\
\text { velocity }\left(\mathrm{m} \mathrm{s}^{-1}\right)\end{array}$ & -0.17 & -0.14 & -0.32 \\
\hline $\begin{array}{l}\text { Average TKE } \\
\text { dissipation rate } \\
\left(\mathrm{m}^{2} \mathrm{~s}^{-3}\right)\end{array}$ & $7 \times 10^{-4}$ & $16 \times 10^{-4}$ & $19 \times 10^{-4}$ \\
\hline
\end{tabular}


small and very similar for all the events $\left(\approx 1.5 \mathrm{~m} \mathrm{~s}^{-1}\right)$. Large differences in reflectivity, Doppler velocity and TKE dissipation rate are found between fog, near-fog and clear events, and the values shown in Table 2 correspond to the vertical average between cloud base and cloud top. Doppler velocity (vertical air motion + droplet terminal fall velocity) for clear events $\left(-0.32 \mathrm{~m} \mathrm{~s}^{-1}\right)$ is twice as large as during fog events $\left(-0.17 \mathrm{~m} \mathrm{~s}^{-1}\right)$. Hence the presence of larger droplets tends to increase the height of the stratus cloud layer (see explanation in the next part). The opposite tendency is observed for the TKE dissipation rate; TKE dissipation rate inside the stratus cloud for the clear periods is three times smaller than for fog events $\left(\varepsilon=7 \times 10^{-4}\right.$ and $19 \times 10^{-4} \mathrm{~m}^{2} \mathrm{~s}^{-3}$, respectively). The increase in evaporation at cloud base induces a decoupling between the surface and cloud and therefore the dissipation of the fog. A more detailed description of the role of drizzle evaporation will be provided in a later section.

This 6-day period is characterized by an inversion height ranging from 400 to $800 \mathrm{~m}$ depending on the stratus top altitude. On 23 December 2006 at 1200 UTC (i.e. just before the formation of the stratus cloud) the inversion height is $420 \mathrm{~m}$ a.g.l. with a lapse rate of $-8.5 \mathrm{~K} \mathrm{~km}^{-1}$ observed up to the inversion level. Such a negative lapse rate is a necessary condition for the existence of the stratus fog (Oliver et al. 1978). During this entire stratus cloud event, the lapse rate inside the cloud was ranging from -6 to $-9 \mathrm{~K} \mathrm{~km}^{-1}$. The variations in temperature and relative humidity at cloud top inside a very thin transition region of around $40 \mathrm{~m}$ reach $10^{\circ} \mathrm{C}$ and $50 \%$, respectively. Infrared radiative cooling related to the liquid droplet emissivity is responsible for cooling at cloud-top height and hence the wet adiabatic cooling inside the stratus cloud layer.

The PM2.5 mass concentration is monitored by a tapered element oscillating microbalance. The PM2.5 mass concentration ranges from 5 to $35 \mu \mathrm{g} \mathrm{m}^{-3}$ during this 6-day period, with PM2.5 and PM10 very well correlated (correlation coefficient of 0.91 ). We do not note significant correlation with the $\mathrm{CBH}$ and the PM2.5 (correlation coefficient of 0.51). However, the three minimum values of PM2.5 are found at the same time as the three major fog events (see Table 2). The average PM2.5 mass concentration for fog, near fog and clear events is 12,22 and $24 \mu \mathrm{g} \mathrm{m}^{-3}$, respectively, and appears to indicate that the PM2.5 is activated during a fog event and hence the droplets are not included in the PM2.5 mass concentration. The PM2.5 mass concentration experiences a decrease from 25 to $5 \mu \mathrm{g} \mathrm{m}^{-3}$ between the 24 and 26 December 2006 phases with a progressive but constant decrease of the visibility (decreasing from $10 \mathrm{~km}$ to $300 \mathrm{~m}$ ). On 28 December 2006, when the wind direction changes, the visibility follows the same trend during this time. On 27 December between 1500 and 1700 UTC, the wind direction and the wind speed range from westerly to southerly and from 3 to $1 \mathrm{~m} \mathrm{~s}^{-1}$, respectively. This non-polluted air mass does not affect the simultaneous decrease of the visibility and PM2.5 mass concentration.

\section{Stratus-Fog Formation and Dissipation}

\subsection{Coupling with the Surface Temperature and Humidity}

Fog is a boundary-layer phenomenon; therefore, its formation and evolution are strongly influenced by surface conditions that are determined by the properties, and current state, of soil and canopy (vegetation or urban) for land fogs (Siebert et al. 1992). Figure 2 shows the time series of the $\mathrm{CBH}$ derived from the ceilometer backscatter signal (Morille et al. 2007) and calculated using the concept of lifting condensation level (noted LCL). This LCL concept makes the assumption that well-mixed conditions are present in the lower atmosphere 
and that the vertical profile of water vapour mixing ratio is constant until cloud base where saturated conditions are reached. In this study, CBH measurements and LCL agree well except when in-cloud dynamics change significantly. This will be explained in more detail in Sect. 3.2. A comparison between LCL and ceilometer CBH allows us to calculate the slope of this relationship, reaching 0.91 with an intercept around $-62 \mathrm{~m}$ and a root-mean-square error $<37 \mathrm{~m}$ for this dataset. For this calculation, the period when the $\mathrm{CBH}$ is inside the blind zone of the ceilometer is not considered (i.e. fog event). The bottom panel in Fig. 2 shows the absolute difference between modelled and measured $\mathrm{CBH}$ and the horizontal visibility. A possible source of discrepancy between the LCL and measured CBH could be explained by a ceilometer retrieval bias of $20-30 \mathrm{~m}$. The $\mathrm{CBH}$ derived from the ceilometer algorithm is found to be 20-30 m higher than the "true $\mathrm{CBH}$ " that can be derived from visual inspection. Another source of uncertainty could be the temperature and humidity accounted for in the calculation: we consider here the 2 -m properties but an average temperature and humidity between the surface and $30 \mathrm{~m}$ a.g.l. would be more representative of surface parcels. Below, we consider that we have a good agreement when the difference between the measured cloud-base altitude and the LCL is $<60 \mathrm{~m}$.

The two main important lifting-stratus periods between 24 December 0600 and 2200 UTC and between 26 December 0300 and 2400 UTC are very well documented by the LCL (Fig. 2). This agreement shows the role of the coupling between temperature and humidity close to the ground and the altitude of the saturated parcel. For example, the fog event between 25 December 1900 UTC and 26 December 0300 UTC is very well reproduced by the LCL concept. This case will be detailed in a following section. However, during this 6-day period important discrepancies between the CBH and LCL are also observed: (1) a 2-h temporal shift on 24 December at 0600 UTC and on 28 December at 0300 UTC due to the effects of in-cloud dynamics occurring during fog dissipation, (2) a 250-m difference between measured CBH and LCL due to the effect of higher altitude clouds on incloud dynamics. These specific periods are noted in Fig. 2 and are discussed in more detail below.
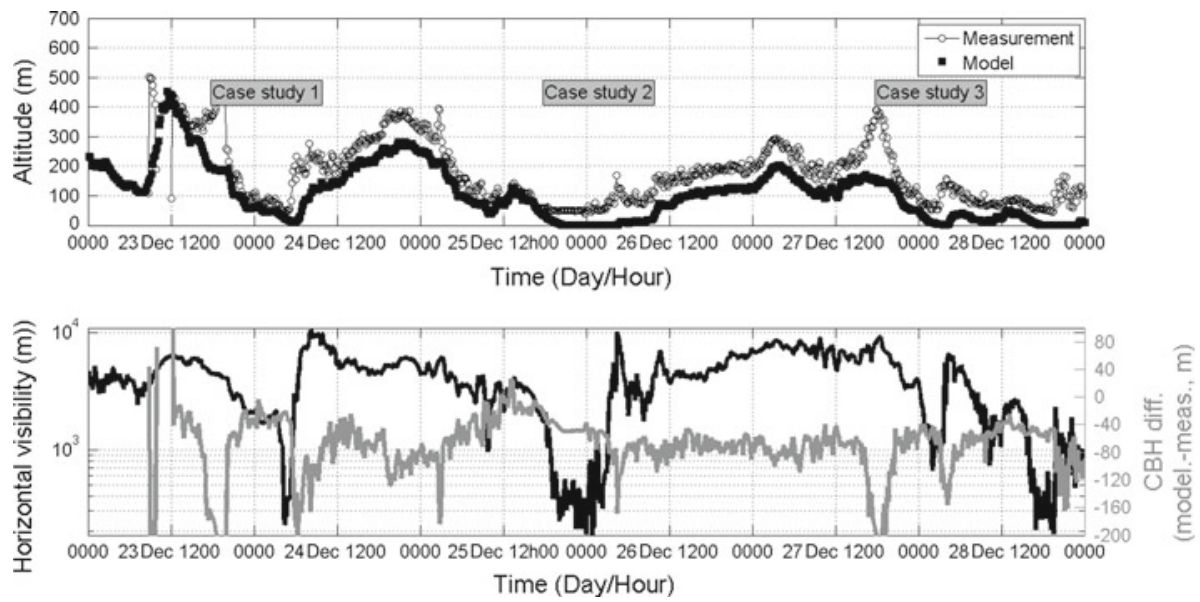

Fig. 2 Time series of the measured and modelled $\mathrm{CBH}$ for the 6-day stratus cloud event at the top panel. Absolute difference between modelled and measured $\mathrm{CBH}$ in grey line and horizontal visibility in black line in bottom panel 


\subsection{Effects of In-Cloud Dynamics During Case Study 1}

The reflectivity measured by the RASTA cloud radar is mainly sensitive to droplet size ( $\mathrm{Z} \propto D^{6}$ where $D$ is the droplet diameter), but is also sensitive to droplet concentration (Battan 1973). The vertical Doppler velocity corresponds to the sum of vertical droplet velocity and vertical air velocity (noted here as positive for upward velocity). In this study, we use the Doppler velocity as a proxy of vertical droplet velocity assuming that the mean vertical air velocity is negligible. The TKE dissipation rate is correlated to the turbulent mixing within the cloud layer (Bouniol et al. 2003). Figure 3 shows in-cloud properties provided by the RASTA cloud radar between 23 December 1200 and 24 December 1200 UTC, where we add the cloud-base altitude derived from the ceilometer (solid line) and from the LCL calculation (dashed line). The two large vertical dash-dot lines correspond to the fog period characterized by a horizontal visibility below $1000 \mathrm{~m}$ (minimum of $240 \mathrm{~m}$ at 0430 UTC).

The fog period commences at 0400 UTC and ends at 0530 UTC; however, the history of this stratus fog covers a much longer time span. In fact, the favourable conditions began at 2000 UTC when the stratus forms at $200 \mathrm{~m}$ above ground level. Over seven hours (2000-0300 UTC), cloud-top radiative cooling induces a progressive and slow lowering of the cloud-base height. Cloud-top infrared cooling induces droplet growth at cloud top $(Z \approx-22 \mathrm{dBZ}$ at cloud top and $-30 \mathrm{dBZ}$ at cloud base) with a relatively low vertical Doppler velocity near $-0.1 \mathrm{~m} \mathrm{~s}^{-1}$, constant between cloud base and cloud top. Droplets fall slowly to and beyond cloud base leading to cooling of the sub-cloud layer by evaporation and to lowering the saturation level (LCL). The stratus base lowering from 200 to $100 \mathrm{~m}$ in seven hours appears to be a slow evolving process. The $2-\mathrm{m}$ relative humidity increases from 90 to $98 \%$ and the $2-\mathrm{m}$ temperature increases from 1.2 to $2^{\circ} \mathrm{C}$. The near-surface moistening and warming may be the result of competing processes between evaporating cooling/moistening and radiative warming. The good agreement between the LCL and CBH measured by the ceilometer is an indicator of strong coupling between the surface and cloud base. This coupling could be explained by evaporation at cloud base, which cools the top of the sub-cloud layer. Negative buoyancy of cooled air destabilizes the sub-cloud layer and triggers turbulent mixing and hence coupling between surface and cloud base.

Between 0300 and 0600 UTC, we observe a radical change in in-cloud reflectivity, Doppler velocity and TKE dissipation rate. This transient period can be divided into two parts: the first one leading to fog formation and persistence of fog conditions during $90 \mathrm{~min}$ and the second leading to rapid fog dissipation.

Between 0300 and 0400, the in-cloud Doppler velocity is drastically modified with a significant increase at cloud base: Doppler velocity increases from -0.1 to $-0.7 \mathrm{~m} \mathrm{~s}^{-1}$ and the reflectivity becomes more homogeneous between cloud base and cloud top ( $Z \approx-22 \mathrm{dBZ}$ ). The fall of the larger droplets induces an increase in Doppler velocity. During the same period, the TKE dissipation rate $\varepsilon$ at cloud base increases from $10^{-4}$ to $10^{-3} \mathrm{~m}^{2} \mathrm{~s}^{-3}$. This transient step is characterized by heterogeneous turbulence ( $\varepsilon$ ranging from $10^{-3}$ at cloud base, $10^{-4}$ in mid-regions and $5 \times 10^{-3} \mathrm{~m}^{2} \mathrm{~s}^{-3}$ at cloud top). After $0400 \mathrm{UTC}$, the droplet size increases at cloud base $(Z \approx-20 \mathrm{dBZ})$, Doppler velocity reaches $-0.7 \mathrm{~m} \mathrm{~s}^{-1}$ at $180 \mathrm{~m}$ a.g.l. while visibility decreases below $1 \mathrm{~km}$ at the surface.

During the fog event, i.e between 0400 and 0530 UTC, the reflectivity $Z$ and the Doppler velocity reach $-5 \mathrm{dBZ}$ and $-1.1 \mathrm{~ms}^{-1}$ at $180 \mathrm{~m}$ a.g.l., respectively. This maximum negative Doppler velocity around $-1 \mathrm{~ms}^{-1}$ is a typical value for the fall speed of a drizzle drop of $0.25 \mathrm{~mm}$ diameter, assuming it is spherical (i.e a volume of $0.008 \mathrm{~mm}^{3}$ ). The larger droplets fall to the ground with a quasi-homogeneous velocity within the cloud (average Doppler velocity around $-0.6 \mathrm{~m} \mathrm{~s}^{-1}$ ) while saturated conditions prevail all the way down to 
(a)

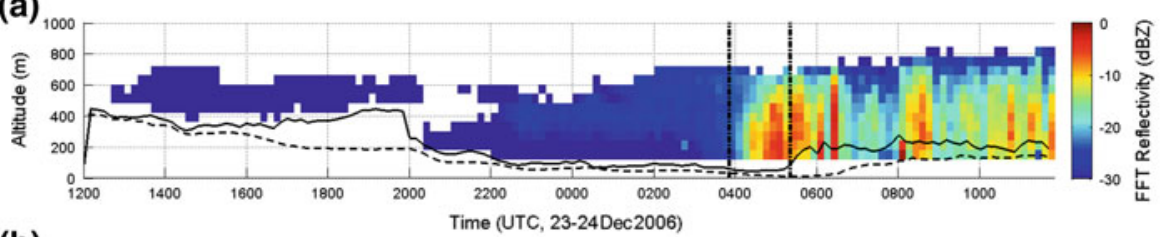

(b)

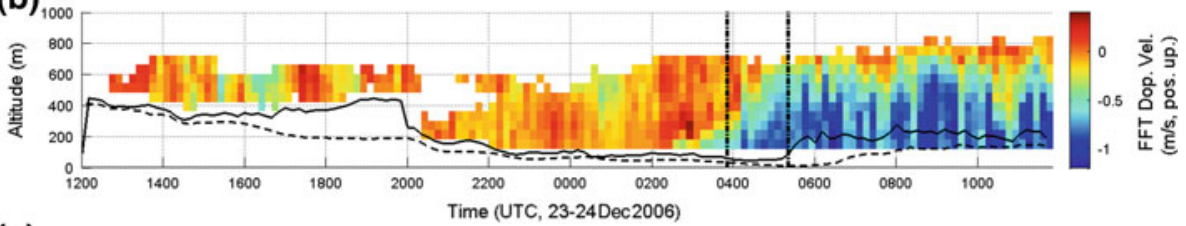

(c)

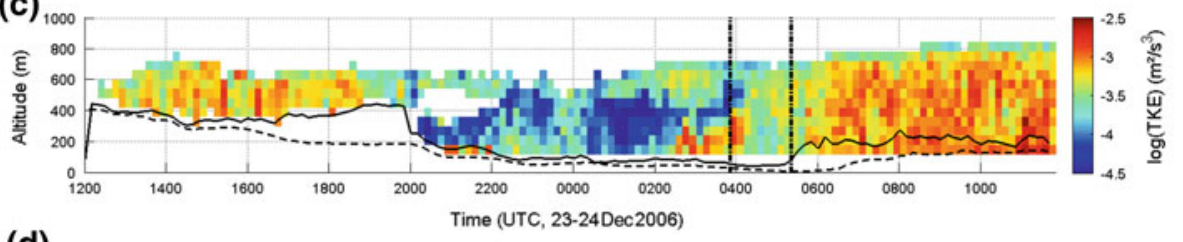

(d)

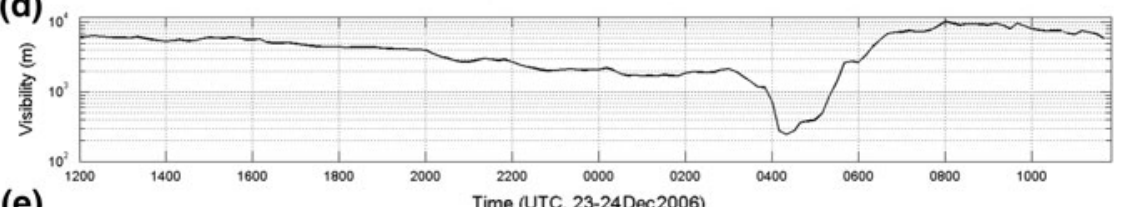

(e) Time (UTC, 23-24Dec2006)

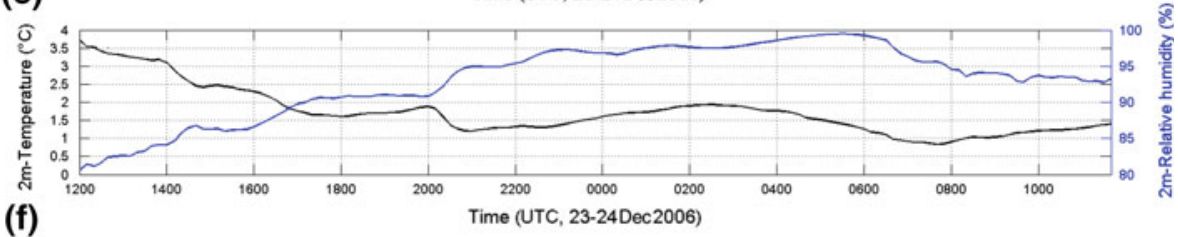

(f)

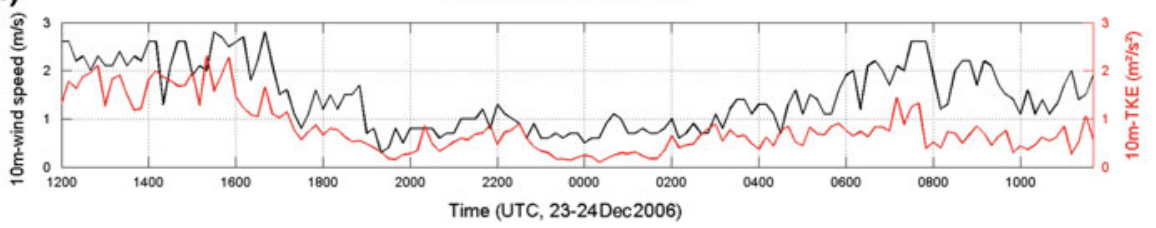

Fig. 3 The time series corresponds to the period between 23 December 1200 UTC and 24 December 1200 UTC. The graphs $\mathbf{a}-\mathbf{c}$ are the radar reflectivity, the Doppler velocity and the TKE dissipation rate, respectively. Solid line is the cloud base detected by the CT25K ceilometer and the dashed line is the LCL. The graphs d-f correspond to the horizontal visibility, surface temperature and humidity, and 10-m wind speed and 10-m TKE

the surface. These drizzle drops contribute themselves to lowering the visibility below the fog threshold. This phase is characterized by a relatively low turbulence intensity inside the fog with $\varepsilon \approx 5 \times 10^{-4} \mathrm{~m}^{2} \mathrm{~s}^{-3}$. This could be explained by the more homogeneous Doppler velocity throughout the cloud.

At 0530 UTC, $Z$ reaches a maximum and is almost constant inside the cloud (between surface and $750 \mathrm{~m}$ a.g.l.). Negative Doppler velocities near $-1 \mathrm{~m} \mathrm{~s}^{-1}$ appear from surface to cloud top. As droplet size and number reach a maximum, the cloud base begins to lift and 
the fog starts to dissipate. A possible scenario is that the persistent radiative cooling at cloud top induces continuous droplet growth and intensification of drizzle leading to increased collection of the smaller fog droplets by the drizzle drops and hence dissipation of the fog by removal of liquid water content. The typical size of a drizzle drop is $0.25 \mathrm{~mm}$ while the maximum of the fog droplet distribution is around $15 \mu \mathrm{m}$ (Elias et al. 2009) which induces a collection efficiency around 90\% (Hall 1980; Wood et al. 2009). Hence, the dissipation of the fog could be due to the strong collection effect close to the surface leading to the fall of the major part of the largest droplets to the ground.

At 0600 UTC, the cloud-base altitude provided by the CT25K ceilometer is $120 \mathrm{~m}$ higher than that from the radar, which is consistent with drizzle particles below cloud base. The surface temperature decreases from 1.5 to $1.0^{\circ} \mathrm{C}$ between 0530 and $0630 \mathrm{UTC}$ and the relative humidity decreases from 100 to $97 \%$. It is likely that the $\mathrm{CBH}$ rises because the cloud loses water though precipitation of large particles while surface conditions remain unchanged, resulting in a constant LCL.

Cloud-base height levels off near $200 \mathrm{~m}$ a.g.l. at 0630 UTC, while the LCL levels off below $200 \mathrm{~m}$ a.g.l. after 1000 UTC, $2 \mathrm{~h}$ after sunrise. During that time frame, the stratus cloud is characterized by temporally varying reflectivity with a negative vertical profile of reflectivity (low reflectivity at cloud top), negative Doppler velocity throughout the cloud, except at cloud top and a significant TKE dissipation rate throughout the cloud. This period is also characterized by drizzle below cloud base, evidenced by a ceilometer $\mathrm{CBH}$ located higher than the lowest reflectivity signal. It is thus likely that evaporation of drizzle at cloud base continues to occur throughout this period, hence continuously cooling the sub-cloud layer from the top. Positive surface heat fluxes and negative buoyancy at the top result in a well mixed sub-cloud layer.

For this case study, the stratus to fog transition is presented as the following conceptual model: a steady-state period (seven hours) characterized by a slow continuous cloudbase lowering followed by a rapid transient period conducting to fog formation and dissipation (two hours). During the 7-h period, continuous cloud-top radiative cooling (around $-160 \mathrm{~W} \mathrm{~m}^{-2}$ ) induces a progressive and slow lowering of the $\mathrm{CBH}$ : larger droplets at cloud top $(Z \approx-20 \mathrm{dBZ}$ ) induce slow droplet fall to and beyond cloud base (Doppler velocity $\left.-0.1 \mathrm{~m} \mathrm{~s}^{-1}\right)$ cooling the sub-cloud layer by evaporation and lowering the saturation level progressively to $100 \mathrm{~m}$. The moistening ( $+8 \%$ for relative humidity) and the warming $\left(+0.8^{\circ} \mathrm{C}\right.$ for temperature) close to the surface could be the result of competing radiative and evaporating processes. Suddenly, a significant increase of Doppler velocity (velocity $\approx-0.6 \mathrm{~m} \mathrm{~s}^{-1}$ ) and of TKE dissipation rate $\left(\varepsilon \approx 10^{-3} \mathrm{~m}^{2} \mathrm{~s}^{-3}\right)$ occurs at cloud base. These turbulent eddies act inside the cloud to mix the properties across the whole layer between cloud base and cloud top enlarging droplet size at cloud base by collection processes. These larger cloud droplets reach the surface leading to fog formation over $1.5 \mathrm{~h}$. The Doppler velocity continues to increase over the entire cloud depth with a maximum near the surface $\left(\approx-1 \mathrm{~m} \mathrm{~s}^{-1}\right)$ due to collection of fog droplets by the drizzle drops with high collection efficiency (around 90\%) enlarging the droplet size. As particles become larger, they fall to the ground leading to fog dissipation. Hence, falling particles play a major role in both the formation and dissipation of the fog. These roles co-exist and the balance is driven by the characteristics of the falling particles such as the concentration of drizzle drops (decoupling or not between cloud layer and surface), size distribution of drizzle drops compared to fog droplets (collection of the fog droplet or not), Doppler velocity (deposit on the ground or not) and thermodynamic state close to the surface (warming of the atmosphere close to the surface or not). Table 3 summarizes typical values of in-cloud properties, radiative properties and near-surface thermodynamic properties observed during stratus-lowering, fog and stratus-rising stages of stratus-to-fog transitions. 
Table 3 In-cloud properties (case 1 and case 3 in italic), radiative properties and near-surface thermodynamic properties leading to the stratus lowering, the fog formation and the stratus lifting

\begin{tabular}{|c|c|c|c|}
\hline & Stratus lowering $\rightarrow$ & Fog formation $\rightarrow$ & Stratus lifting \\
\hline \multicolumn{4}{|l|}{ In-cloud properties } \\
\hline Droplet size and conc. & $-25 \mathrm{dBZ}\left(+10 \mathrm{dBZ} \mathrm{km}^{-1}\right)$ & $-20 \mathrm{dBZ}$ (stable) & $-5 \mathrm{dBZ}\left(-20 \mathrm{dBZkm}^{-1}\right)$ \\
\hline Radar reflectivity $(Z)$ & $-27 \mathrm{dBZ}\left(+5 \mathrm{dBZkm}^{-1}\right)$ & $-23 \mathrm{dBZ}$ (stable) & $-15 \mathrm{dBZ}\left(-10 \mathrm{dBZ} \mathrm{km}^{-1}\right)$ \\
\hline Vertical velocity $\left(\mathrm{ms}^{-1}\right)$ & -0.2 & -0.1 & -0.8 \\
\hline \multicolumn{4}{|l|}{ Doppler velocity $(D V)$} \\
\hline $\begin{array}{l}\text { In-cloud turbulence } \\
\left(\mathrm{m}^{2} \mathrm{~s}^{-3}\right) \\
\text { TKE dissipation rate }(\varepsilon)\end{array}$ & $1 \times 10^{-4}$ & $5 \times 10^{-4}$ & $10 \times 10^{-4}$ \\
\hline \multicolumn{4}{|l|}{ Radiative properties $\left(\mathrm{W} \mathrm{m}^{-2}\right)$} \\
\hline Infrared cooling & -160 & & -130 \\
\hline \multicolumn{4}{|c|}{ Near-surface thermodynamic properties } \\
\hline Horizontal wind speed $\left(\mathrm{m} \mathrm{s}^{-1}\right)$ & 1 & & 3 \\
\hline $\operatorname{TKE}\left(\mathrm{m}^{2} \mathrm{~s}^{-2}\right)$ & 0.75 & 0.25 & 1.75 \\
\hline Vertical wind speed $\left(\mathrm{m} \mathrm{s}^{-1}\right)$ & -0.1 & & +0.2 \\
\hline Temperature $\left({ }^{\circ} \mathrm{C}\right)$ & 1.8 & 1.4 & 1.2 \\
\hline Humidity (\%) & $94-99$ & 100 & $92-99$ \\
\hline
\end{tabular}

These values correspond to the key thresholds favourable for each different process

\subsection{Effects of Surface Dynamics During Case Study 2}

A deep and long-lived fog event occurred between 25 December at 1900 and 26 December at 0300 UTC (Fig. 4). The lowest visibility is $200 \mathrm{~m}$ and appears at 0100 UTC associated with a weak subsidence event with a vertical wind speed around $-0.01 \mathrm{~m} \mathrm{~s}^{-1}$. This fog event is associated with a continuous decrease (increase) in temperature (relative humidity) from 0.5 to $-1{ }^{\circ} \mathrm{C}(94-100 \%)$ between 1300 and 0400 UTC. The horizontal wind speed is relatively low (ranging from 0.5 to $2.5 \mathrm{~m} \mathrm{~s}^{-1}$ ) and the stratus-cloud thickness is less than $200 \mathrm{~m}$.

The changes in visibility between 0000 and 0200 UTC ranging from $200 \mathrm{~m}$ to $1 \mathrm{~km}$ are temporally correlated with surface dynamics, enhanced reflectivity and vertical velocities. Horizontal wind-speed fluctuations close to the ground range between 0.8 and $2 \mathrm{~m} \mathrm{~s}^{-1}$, Doppler velocity inside the cloud from -0.1 to $-0.5 \mathrm{~m} \mathrm{~s}^{-1}$ and reflectivity from -30 to $-18 \mathrm{dBZ}$. Three visibility minima appear at 0000,0045 and 0200 UTC and two maxima at 0030 and 0115 UTC. The minimum of visibility is phased with a minimum of the TKE (horizontal wind speed) at $10 \mathrm{~m}$ a.g.l. of $0.25 \mathrm{~m}^{2} \mathrm{~s}^{-2}\left(0.8 \mathrm{~m} \mathrm{~s}^{-1}\right)$ and with a peak of cloud reflectivity and Doppler velocity reaching $-15 \mathrm{dBZ}$ and $-0.5 \mathrm{~m} \mathrm{~s}^{-1}$, respectively. A possible explanation is that when the horizontal wind speed is low (surface wind speed < $1 \mathrm{~m} \mathrm{~s}^{-1}$ ), radiative cooling at cloud top leads to droplet growth and increased droplet fall velocity. Larger droplets and drizzle drops combined with high droplet concentration ( $Z$ around $-15 \mathrm{dBZ}$ at $200 \mathrm{~m}$ ) tend to lower the visibility. Conversely, a larger horizontal wind speed $\left(\approx 2 \mathrm{~m} \mathrm{~s}^{-1}\right.$ ) inside the fog leads to a uniform vertical profile of reflectivity ( $Z$ around $-25 \mathrm{dBZ}$ at $200 \mathrm{~m}$ ) and a uniform Doppler velocity near zero within the entire fog layer. This is synonymous with a low concentration of smaller droplets resulting in higher visibility close to the surface. 

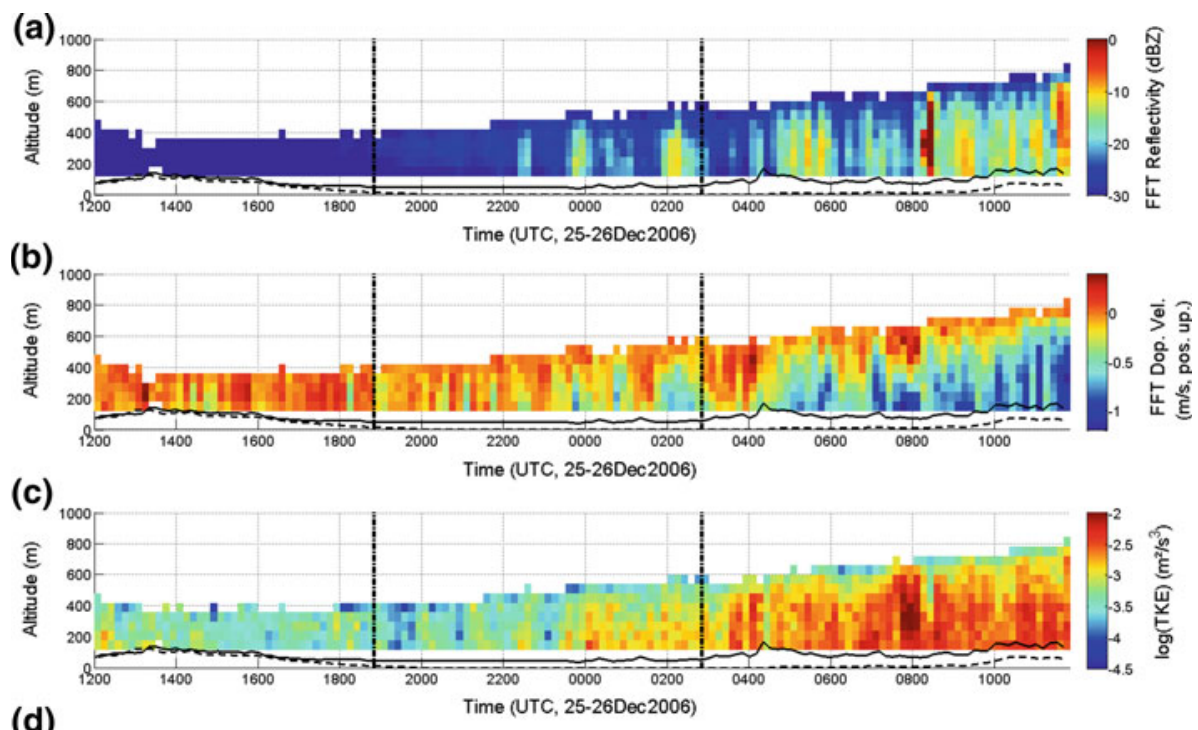

(d)

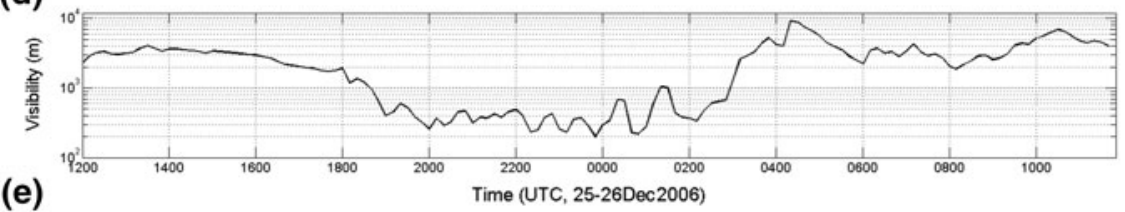

(e)

Time (UTC, 25-26Dec2006)
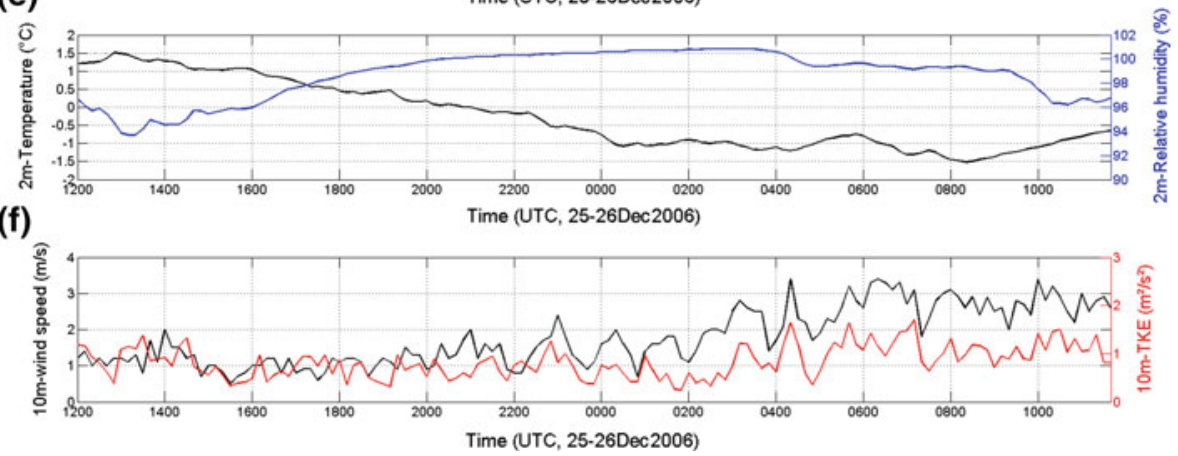

Fig. 4 The time series corresponds to the period between 25 December 1200 UTC and 26 December 1200 UTC. The graphs $\mathbf{a}-\mathbf{c}$ are the radar reflectivity, the Doppler velocity and the TKE dissipation rate, respectively. Solid line is the cloud base detected by the CT25K ceilometer and the dashed line is the LCL. The graphs d-f correspond to the horizontal visibility, surface temperature and humidity, and 10-m wind speed and 10-m TKE

Between 0200 and 0430 UTC, visibility progressively increases up to $5 \mathrm{~km}$ and the $\mathrm{CBH}$ rises to $100 \mathrm{~m}$ a.g.l. During this important increase of visibility, the in-cloud reflectivity decreases ( -15 to $-26 \mathrm{dBZ}$ ) and the precipitation ceases (particle velocity near zero) whereas the horizontal wind speed reaches $3 \mathrm{~m} \mathrm{~s}^{-1}\left(1 \mathrm{~m} \mathrm{~s}^{-1}\right.$ at $\left.0200 \mathrm{UTC}\right)$. TKE at $10 \mathrm{~m}$ a.g.l., correlated to turbulent mixing near the surface is also increased during the 0200-0330 period with maximum values of $1.25 \mathrm{~m}^{2} \mathrm{~s}^{-2}$ while being $0.25 \mathrm{~m}^{2} \mathrm{~s}^{-2}$ before 0200 UTC. During the 0200-0400 UTC period, the simultaneous decrease in reflectivity and in Doppler velocity, and the increase of the vertical wind speed (reaching $+0.07 \mathrm{~m} \mathrm{~s}^{-1}$ ) close to the surface induced the dissipation of the fog. A possible scenario here is that the soil temperature just below 
the ground surface $(-50 \mathrm{~mm})$ is $+3^{\circ} \mathrm{C}$ while the 2 - $\mathrm{m}$ air temperature is around $-1{ }^{\circ} \mathrm{C}$. This implies a positive upward heat flux leading to the evaporation of fog droplets, increased surface turbulence with a constant surface temperature. The cloud base begins to rise due to the near-surface turbulence that induces mixing and evaporation of the droplets in the sub-cloud layer. A means of better understanding these different aspects would be to document the vertical profile of dynamical properties between the surface and the top of the boundary layer - see below.

\subsection{Effects of Radiative Cooling, In-Cloud and Surface Dynamics During Case Study 3}

On 27 December, a persistent high-altitude cloud around $7.2 \mathrm{~km}$ high is found between 1100 and 1530 UTC (not shown). The cloud-top longwave radiative budget is defined as the difference between the downwelling and the upwelling longwave fluxes at the cloud top, $L W_{\mathrm{dn}}$ and $L W_{\text {up }}$ respectively. Here $L W_{\mathrm{dn}}$ corresponds to the sum of the longwave irradiance emitted by the high altitude cloud and the longwave irradiance emitted by the clear sky. The first is computed from Stephan-Boltzmann's law (Angström 1918) on the basis of the cirrus cloud infrared emissivity and thermodynamic temperature. The cloud infrared emissivity can be derived from the cloud optical thickness on the basis of a parametric relationship (Rossow et al. 1996). The cloud thermodynamic temperature is derived by combining the radiosonde and the radar measurements that provide temperature profiles and cloud-base altitude. The temperatures are interpolated between radiosoundings at the time and altitude of radar observations. A CALIPSO (cloud-aerosol lidar and infrared pathfinder satellite observations) overpass (Winker et al. 2009) over the SIRTA site at the same time provides collocated measurements of the cloud optical thickness for this high altitude cloud. The optical thickness is relatively constant at 0.2 and the derived infrared emissivity $\gamma$ is about 0.16 (Rossow et al. 1996). The longwave irradiance emitted by the cirrus cloud is calculated from $\gamma \sigma T^{4}$ (where $T$ is the cirrus radiative temperature and $\sigma$ is Stefan-Boltzmann's constant, $\sigma=5.67 \times 10^{-8} \mathrm{~W} \mathrm{~m}^{-2} \mathrm{~K}^{-4}$ ), and ranges between 10 to $35 \mathrm{~W} \mathrm{~m}^{-2}$. The same relation is applied for the clear atmosphere longwave flux with $\gamma$ representing the clear-sky emissivity of the atmosphere. It can be expressed as a function of cloud-top air temperature and water vapour pressure (Brutsaert 1975; Dupont et al. 2007). Finally, $L W_{\text {up }}$ at cloud-top is derived considering that the stratus cloud has an emissivity near unity with a cloud-top temperature computed using cloud-top altitude and radiosonde temperature profile. The longwave radiative budget (downwelling minus upwelling fluxes) at cloud top ranges between -162 to $-125 \mathrm{~W} \mathrm{~m}^{-2}$.

Between 1100 and 1530 UTC, the net radiative cooling at cloud top is reduced by $30 \mathrm{~W} \mathrm{~m}^{-2}$ compared to the value before 1100 UTC. This period (1100-1530 UTC) is characterized by low radar reflectivity $-32 \mathrm{dBZ}$, instead of $2 \mathrm{dBZ}$ before $1100 \mathrm{UTC}$ (Fig. 5). Similarly the vertical Doppler velocity becomes close to zero during the 1100-1530 UTC period, while being $-0.3 \mathrm{~m} \mathrm{~s}^{-1}$ on average before 1100 UTC. The TKE dissipation rate is also reduced with average values of $6 \times 10^{-4}$, and $24 \times 10^{-4} \mathrm{~m}^{2} \mathrm{~s}^{-3}$ before 1100 UTC. During the 1100-1530 UTC period, the lidar-based and radar-based $\mathrm{CBH}$ agree, which is evidence that there was no drizzle below cloud base at that time; $\mathrm{CBH}$ rises slightly during these $4 \mathrm{~h}$. The LCL is consistent with the $\mathrm{CBH}$ evidence of coupling between the surface and cloud layer, a reasonable assumption in daytime and under moderate winds (TKE near $1 \mathrm{~m}^{2} \mathrm{~s}^{-2}$ and wind speed around $3 \mathrm{~m} \mathrm{~s}^{-1}$ ).

After 1530 UTC, the high altitude cloud disappears and the stronger radiative cooling reaches $-160 \mathrm{~W} \mathrm{~m}^{-2}$. Between 1530 and $2000 \mathrm{UTC}$, the mean reflectivity increases from 
(a)

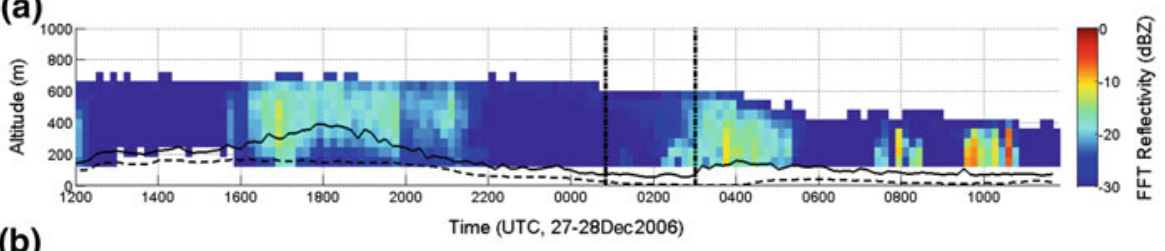

(b)

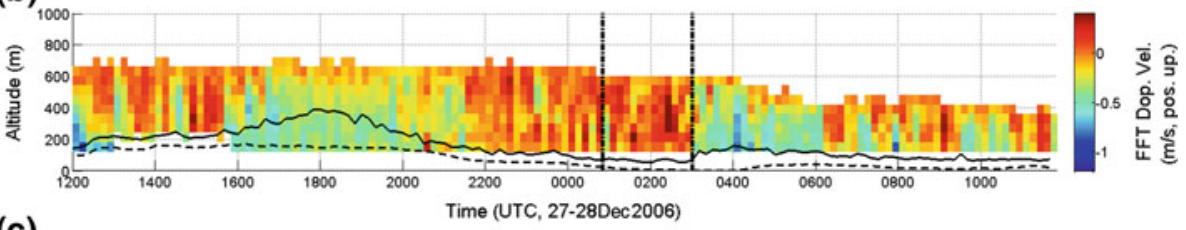

(c)

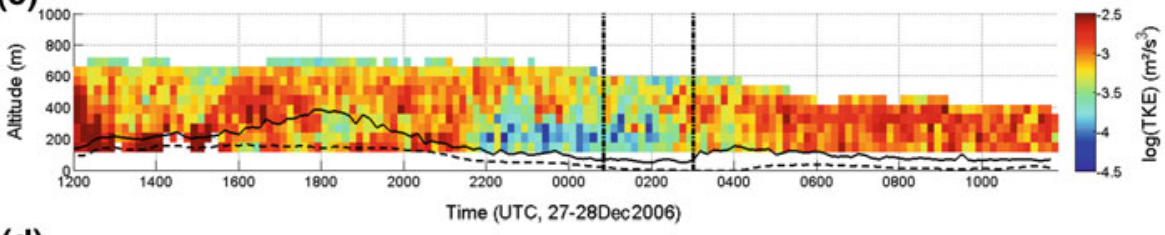

(d)

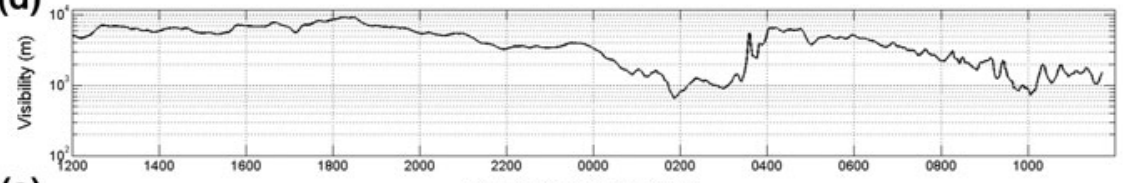

(e)

Time (UTC, 27-28Dec2006)

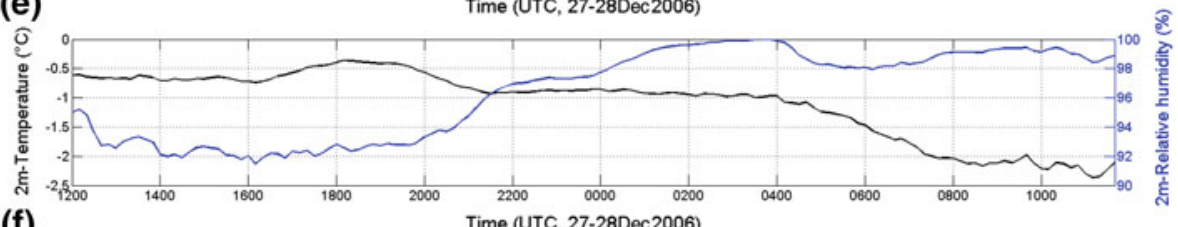

(f) Time (UTC, 27-28Dec2006)

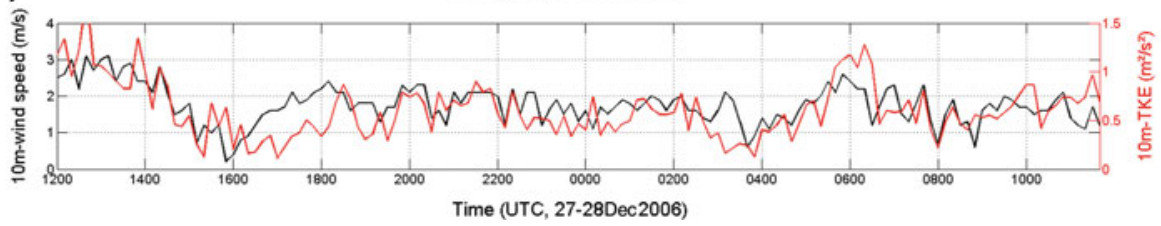

Fig. 5 The time series corresponds to the period between 27 December 1200 UTC and 28 December 1200 UTC. The graphs $\mathbf{a}-\mathbf{c}$ are the radar reflectivity, the Doppler velocity and the TKE dissipation rate, respectively. Solid line is the cloud base detected by the CT25K ceilometer and the dashed line is the LCL. The graphs d-f correspond to the horizontal visibility, surface temperature and humidity, and 10-m wind speed and 10-m TKE

-32 to $-18 \mathrm{dBZ}$ and the mean Doppler velocity increased from zero to $-0.3 \mathrm{~m} \mathrm{~s}^{-1}$. The vertical gradient of reflectivity is positive with $Z=-13 \mathrm{dBZ}$ at cloud top and $Z=-22 \mathrm{dBZ}$ at cloud base. The vertical gradient of the Doppler velocity is positive with Doppler velocity $=-0.1 \mathrm{~m} \mathrm{~s}^{-1}$ at cloud top and Doppler velocity $=-0.5 \mathrm{~m} \mathrm{~s}^{-1}$ at cloud base. Significant drizzle appears below cloud base, as evidenced by the ceilometer CBH $240 \mathrm{~m}$ above the lowest radar return. Drizzle could be due to the collection/coalescence process (strong collection efficiency as shown previously) and the increase of the cloud-top height of $60 \mathrm{~m}$ could 
be related to the condensation process (small droplets and high radiative cooling favour condensation). From 1530 to 2000 UTC, the surface temperature increases from -0.7 to $-0.3^{\circ} \mathrm{C}$ and the relative humidity is stable at $92 \%$, suggesting the moistening of the subcloud layer.

Between 2000 and 0200 UTC, a slow evolving period occurs similar to the conditions encountered in case 1 described in Sect. 3.2. At 2000 UTC, the Doppler velocity and the reflectivity decrease from -0.3 to $-0.1 \mathrm{~m} \mathrm{~s}^{-1}$ and from -17 to $-21 \mathrm{dBZ}$, respectively. Doppler velocity, droplet size, and intensity of drizzle at cloud base decrease. Similarly to case 1, the droplets fall slowly to and beyond cloud base cooling the sub-cloud layer by evaporation. Negative buoyancy in the sub-cloud layer maintains coupling with the surface, as evidenced by the consistency between LCL and CBH lowering, until fog conditions appear at 0130 UTC.

However, we note some differences between case 3 and to case 1. Firstly, between 2130 and 0200 UTC, we observe a significant gradient of the TKE dissipation rate between cloud base $\left(\varepsilon \approx 2 \times 10^{-4} \mathrm{~m}^{2} \mathrm{~s}^{-3}\right)$ and cloud top $\left(\varepsilon \approx 8 \times 10^{-4} \mathrm{~m}^{2} \mathrm{~s}^{-3}\right)$ whereas droplet vertical velocity and reflectivity are low and stable in the vertical. A possible scenario is that the stable in-cloud dynamics is reinforced within $200 \mathrm{~m}$ of cloud base by the evaporative processes tending to stabilize the cloud base. This halts the lowering of cloud layer (cloud base stable at $140 \mathrm{~m}$ between 2200 and 0000 UTC) and induces a constant temperature and humidity close to the surface which may induce a delay in the fog formation. Secondly, the timing for the fog formation is different relative to the increase of reflectivity and Doppler velocity. In case 1, the increase of reflectivity and Doppler velocity is phased with the fog formation whereas here a 1-h delay is noted. We may explain this contrast with the relative humidity difference close to the surface some hours before fog formation: in case 1 the relative humidity is $95 \%$ two hours before the fog formation compared to $98 \%$ for case 3 . In case 1, significant drizzle is necessary to bring cloud base to the ground, whereas in case 3 the slow and progressive lowering of cloud base is sufficient to reach the fog.

Between 0200 and 0500 UTC, the in-cloud reflectivity increases progressively starting from cloud base to reach a maximum of $-10 \mathrm{dBZ}$ relatively stable along the vertical at 0345 UTC. At 0300 , the Doppler velocity suddenly increases from zero to $-0.5 \mathrm{~m} \mathrm{~s}^{-1}$ : the fall of the larger droplets induces an increase in Doppler velocity and an increase in $\varepsilon$ from $5 \times 10^{-4}$ to $10^{-3} \mathrm{~m}^{2} \mathrm{~s}^{-3}$. As with case 1 , fog dissipation at 0300 UTC could be explained by an intensification of drizzle throughout the cloud (surface to $600 \mathrm{~m}$ a.g.l.) increasing the collection of fog droplets by large drizzle drops. The larger drops fall to the ground and the cloud base rises.

The period from 0500 to 1100 UTC is characterized by scenarios already encountered in case study 2. From 0500 to 0700 UTC, under moderate horizontal wind, reflectivity is low $(Z \approx-25 \mathrm{dBZ})$, the Doppler velocity is moderate $\left(\approx-0.5 \mathrm{~m} \mathrm{~s}^{-1}\right)$, surface and cloud layer are coupled, and the CBH subsides progressively. At 0915 UTC, a sudden increase of reflectivity $(Z \approx-7 \mathrm{dBZ})$ and Doppler velocity $\left(\approx-0.4 \mathrm{~m} \mathrm{~s}^{-1}\right)$ is phased with a visibility fall leading to fog conditions after 1 hour. This visibility around $900 \mathrm{~m}$ could be explained by an enhanced concentration of drizzle drops phased with a constant and low surface wind speed around $1 \mathrm{~ms}^{-1}$. Two minutes later, a peak in in-cloud reflectivity at $-5 \mathrm{dBZ}$ occurs phased with a reduction in TKE ranging from 1 to $0.5 \mathrm{~m}^{2} \mathrm{~s}^{-2}$. Low-visibility conditions last only $30 \mathrm{~min}$ as the collection of smaller fog droplets by larger settling drizzle drops falls to the ground. 


\section{Conclusion}

The ParisFog field campaign at the SIRTA instrumented site and more specifically the 6-day period studied between the 23 and 29 December 2006 allows us to study different processes driving the stratus-to-fog transition. A suite of active, passive and in-situ measurements document simultaneously the dynamical, radiative and microphysical processes responsible for the formation and dissipation of three different stratus-fog events.

The 23-29 December period shows multiple transitions between stratus cloud and fog layers based on near-surface horizontal visibility, $\mathrm{CBH}$ derived from ceilometer and cloud radar vertical profiles of reflectivity, Doppler velocity and TKE dissipation rate. The period is characterized by multiple events of cloud-base lowering followed by cloud-base lifting and by stratus-fog layers 200-1,000 m thick. Complex processes combining effects of incloud properties, surface coupling and infrared cooling at cloud top have been identified. Table 3 shows the threshold values of these effects conducive to fog formation and lifting into a stratus layer. These values are averaged during the 6-day period for each stage, which corresponds to sub-sampling of stratus-lowering, fog formation and stratus-lifting periods.

The first major result of this study is the evidence that falling cloud droplets and drizzle drops affect both the formation and dissipation of stratus fog. In conditions of continuous infrared cooling at cloud top (near $-160 \mathrm{~W} \mathrm{~m}^{-2}$ in our case), the cloud-topped boundary layer is destabilized leading to turbulent eddies. This in-cloud dynamics depends on the size distribution of cloud droplets and drizzle drops. In the case of moderate reflectivity and vertical Doppler velocity $\left(Z \approx 15 \mathrm{dBZ}\right.$ and velocity $\left.\approx-0.6 \mathrm{~m} \mathrm{~s}^{-1}\right)$, drizzle drops evaporate below cloud base before they reach the ground, and hence cool the sub-cloud layer. This cooling effect destabilizes the sub-cloud layer, leading to efficient coupling with the surface. This cooling acts also to stabilize the cloud layer itself, hence vertical motions inside the cloud are typically moderate in this phase. In such conditions, and in the absence of other forcings, the cloud base tends to subside progressively. When the Doppler velocity reaches $\approx-1 \mathrm{~m} \mathrm{~s}^{-1}$ with a reflectivity $=-5 \mathrm{dBZ}$, the collection of fog droplets by the drizzle drops is very efficient (i.e near 90\%). Drizzle drops become larger and fall to the surface, reducing the liquid water content and inducing rapid fog dissipation.

A second result of this study is the evidence that stratus-cloud microphysics and dynamics can be affected by higher altitude clouds through an impact on stratus-top radiative cooling. We noted a change of $30 \mathrm{~W} \mathrm{~m}^{-2}$ in the cloud-top infrared budget, from $-160 \mathrm{~W} \mathrm{~m}^{-2}$ (without high altitude cloud) to $-130 \mathrm{~W} \mathrm{~m}^{-2}$ (with high altitude cloud). The $30 \mathrm{~W} \mathrm{~m}^{-2}$ change leads to a modification of the in-cloud dynamics. A clear atmosphere above the stratus cloud increases the intensity of radiative cooling leading to enhance droplet growth and turbulent mixing (i.e. $+10 \mathrm{dBZ}$ compared to situation with high altitude cloud). In a first stage, cloud droplets are larger at the stratus top associated with larger particle velocities. This induces a more rapid redistribution of water in the cloud layer through a larger downward flux of water, leading in a second step to reversing the sign of the vertical gradient of reflectivity $(-5 \mathrm{dBZ}$ at cloud base and $-15 \mathrm{dBZ}$ at cloud top). The droplet velocity may reach $-1 \mathrm{~m} \mathrm{~s}^{-1}$ at cloud base and $-0.2 \mathrm{~m} \mathrm{~s}^{-1}$ at cloud top. These interactions between radiative cooling due to the clear sky above the stratus cloud and the particle velocity induce a subsequent depletion of liquid water content by the enhanced gravitational settling of the larger droplets out of clouds.

The third result of this study is the evaluation of the effect of near-surface thermodynamics on stratus-fog transitions. Horizontal wind speed and TKE affect in-cloud processes such as turbulent mixing, vertical particle velocity and evaporation below cloud base (in conditions of constant cloud-top radiative cooling). At night, low wind speed and TKE, less than 1-2 $\mathrm{m} \mathrm{s}^{-1}$ and $1 \mathrm{~m}^{2} \mathrm{~s}^{-2}$, respectively, are conditions favourable to the progressive lowering of the $\mathrm{CBH}$, 
due to cooling of the sub-cloud layer by evaporation. During daytime, under more vigorous near-surface dynamics (i.e wind speed around $2-3 \mathrm{~m} \mathrm{~s}^{-1}$ ), conditions can be favourable to stratus-cloud lifting. The solar irradiance induces a positive gradient of temperature between the ground and atmosphere, reaching in this study $4^{\circ} \mathrm{C}$, and implying a positive upward heat flux warming the atmosphere close to the surface. This surface heat source combined with increased turbulence leads to the evaporation of fog droplets. Another aspect analyzed here is the variability of visibility during fog events (ranging from 200 to $900 \mathrm{~m}$ ) coincident with the variability in surface wind speed. In fog conditions, we observed that under low levels of turbulence close to the surface (TKE of $1 \mathrm{~m}^{2} \mathrm{~s}^{-2}$ or less), reflectivity and Doppler velocity increase, while visibility decreases. Conversely, under more vigorous turbulence (TKE of $2 \mathrm{~m}^{2} \mathrm{~s}^{-2}$ or more), reflectivity and Doppler velocity decrease, while visibility increases. Hence it is likely that in-cloud turbulence affects the size distribution of droplets and changes the vertical distribution of droplets, hence affecting near-surface visibility.

Acknowledgments The authors would like to thank the Centre National de la Recherche Scientifique (CNRS) and the Centre National d'Etudes Spatiales (CNES) for their support in this study. We extend our acknowledgments to the technical and computer staff of each observatory for taking the observations and making the data set easily accessible. The authors are grateful to the anonymous reviewers for their very useful comments that significantly improved the article.

Open Access This article is distributed under the terms of the Creative Commons Attribution License which permits any use, distribution, and reproduction in any medium, provided the original author(s) and the source are credited.

\section{References}

Angström A (1918) A study of the radiation of the atmosphere. Smithson Misc Collect 65:1-159

Battan LJ (1973) Radar observation of the atmosphere. The University of Chicago Press, Chicago, $324 \mathrm{pp}$

Bergot T, Carrer D, Noilhan J, Bougeault P (2005) Improved site-specific numerical prediction of fog and low clouds: a feasibility study. Weather Forecast 20:627-646

Bergot T, Haeffelin M et al (2008) ParisFog: des chercheurs dans le brouillard. La Météorologie 62:1-10

Bouniol D, Illingworth AJ, Hogan RJ (2003) Deriving TKE dissipation rate within clouds using ground based $94 \mathrm{GHz}$ radar. Preprints, 31st conference on Radar Meteorology, Seattle, WA, American Meteorological Society, pp 193-196. http://ams.confex.com/ams/pdfpapers/63826.pdf

Brutsaert W (1975) On a derivable formula for long-wave radiation from clear skies. Water Resour Res 11:742-744

Dupont JC, Haeffelin M, Drobinski P, Besnard T (2007) Parametric model to estimate clear-sky longwave irradiance at the surface based on vertical distribution of humidity and temperature. J Geophys Res 113. doi:10.1029/2007JD009046

Elias T, Haeffelin M, Drobinski P, Gomes L, Rangognio J, Bergot T, Chazette P, Raut J-C, Colomb M (2009) Particulate contribution to extinction of visible radiation: pollution, haze, and fog. Atmos Res. doi:10. 1016/j.atmosres.2009.01.006

Fuzzi S, Facchini MC, Orsi G, Lind JA, Wobrock W, Kessel M, Maser R, Jaeschke W, Enderle KH, Arends BG, Berner A, Solly A, Kruisz C, Reischl G, Pahl S, Kaminski U, Winkler P, Ogren JA, Noone KJ, Hallberg A, Fierlinger-oberlinninger H, Puwbaum H, Marzorati A, Hansson H-C, Wiedensohler A, Svenningsson IB, Martinsson BG, Schell D, Georgii HW (1992) The Po valley fog experiment 1989. An overview. Tellus 44:448-468

Gultepe I, Tardif R, Michaelides SC, Cermak J, Bott A, Bendix J, Müller MD, Pagowski M, Hansen B, Ellrod G, Jacobs W, Toth G, Cober SG (2007) Fog research: a review of past achievements and future perspectives. Pure Appl Geophys 164:1121-1159

Haeffelin M, Barthès L, Bock O, Boitel C, Bony S, Bouniol D, Chepfer H, Chiriaco M, Cuesta J, Delanoe J, Drobinski P, Dufresne JL, Flamant C, Grall M, Hodzic A, Hourdin F, Lapouge F, Lemaitre Y, Mathieu A, Morille Y, Naud C, Noel V, OH'irok B, Pelon J, Pietras C, Protat A, Romand B, Scialom G, Vautard R (2005) SIRTA, a ground-based atmospheric observatory for cloud and aerosol research. Ann Geophys 23:253-275 
Haeffelin M, Bergot T, Elias T, Tardif R, Carrer D, Chazette P, Colomb M, Drobinski P, Dupont E, Dupont J-C, Gomes L, Musson-Genon L, Pietras C, Plana-Fattori A, Protat A, Rangognio J, Raut J-C, Rémy S, Richard D, Sciare J, Zhang X (2010) PARISFOG: shedding new light on fog physical processes. Bull Am Meteorol Soc 91:767-783. doi:10.1175/2009BAMS2671.1

Hall WD (1980) A detailed microphysical model within a two-dimensional dynamic framework: model description and preliminary results. J Atmos Sci 37:2486-2507

Holets S, Swanson RN (1981) High-inversion fog episodes in Central California. J Appl Meteorol 20:890-899

Koracin D, Lewis J, Thompson WT, Dorman CE, Businger JA (2000) Transition of stratus into fog along the California coast: observations and modeling. J Atmos Sci 58:1714-1731

Morille Y, Haeffelin M, Drobinski P, Pelon J (2007) STRAT: An automated algorithm to retrieve the vertical structure of the atmosphere from single-channel lidar data. J Atmos Oceanic Technol 24:761-775. doi:10. 1175/JTECH2008.1

Müller MD, Schmutz C, Parlow E (2007) A one-dimensional ensemble forecast and assimilation system for fog prediction. Pure Appl Geophys 164:1241-1264

Musson-Genon L (1987) Numerical simulations of a fog event with a one- dimensional boundary layer model. Mon Weather Rev 115:592-607

O'Connor EJ, Hogan RJ, Illingworth AJ (2005) Retrieving stratocumulus drizzle parameters using Doppler radar and lidar. J Appl Meteorol 44:14-27

Ohmura A et al (1998) Baseline Surface Radiation Network (BSRN/WCRP): new precision radiometry for climate research. Bull Am Meteorol Soc 79(10):2115-2136. doi:10.1175/1520-0477(1998)079<2115: BSRNBW>2.0.CO;2

Oliver DA, Lewellen WS, Williamson GG (1978) The interaction between turbulent and radiative transport in the development of fog and low-level stratus. J Atmos Sci 35:301-316

Pagowski M, Gultepe I, King P (2004) Analysis and modeling of an extremely dense fog event in southern Ontario. J Appl Meteorol 43:3-16

Pilié RJ, Mack EJ, Kocmond WC, Rogers CW, Eadie WJ (1975) The life cycle of valley fog. Part I: Micrometeorological characteristics. J Appl Meteorol 14:347-363

Protat A, Pelon J, Testud J, Grand N, Delville P, Laborie P, Vinson J-P, Bouniol D, Bruneau D, Chepfer H, Delanoë J, Haeffelin M, Noël V, Tinel C (2004) Le projet RALI: Combinaison d'un radar nuage et d'un lidar pour l'étude des nuages faiblement précipitants. La Météorologie 8 e série 47:23-33

Rossow WB, Walker AW, Beuschel D, Roitier M (1996) International Satellite Cloud Climatology Project (ISCCP): description of new cloud dataset. World Climate Research Programme, Geneva, WMO/TD-737, $115 \mathrm{pp}$

Ryznar E (1977) Advection-radiation fog near Lake Michigan. Atmos Environ 11:427-430

Shupe M, Kollias P, Poellot M, Eloranta E (2007) On deriving vertical air motions from cloud radar Doppler spectra. J Atmos Oceanic Technol 25:547-557

Siebert J, Bott A, Zdunkowski W (1992) Influence of a vegetation-soil model on the simulation of radiation fog. Beitr Phys Atmos 65:93-106

Tag PM, Peak JE (1996) Machine learning of maritime fog forecast rules. J Appl Meteorol 35:714-724

Tardif R (2007) The impact of vertical resolution in the explicit numerical forecasting of radiation fog: a case study. Pure Appl Geophys 164:1221-1240

Tardif R, Rasmussen RM (2007) Event-based climatology and typology of fog in the New York City region. J Appl Meteorol Climatol 46:1141-1167

Telford J, Chai SK (1984) Inversions and fog, stratus and cumulus formation in warm air over cooler water. Boundary-Layer Meteorol 29:109-137

Underwood SJ, Ellrod GP, Kuhnert AL (2004) A multiple-case analysis of nocturnal radiation-fog development in the central valley of California utilizing the GOES nighttime fog product. J Appl Meteorol 43:297-311

Winker DM, Vaughan MA, Omar AH, Hu Y, Powell KA, Liu Z, Hunt WH, Young SA (2009) Overview of the CALIPSO mission and CALIOP data processing algorithms. J Atmos Oceanic Technol 26:2310-2323. doi:10.1175/2009JTECHA1281.1

Wood R, Kubar TL, Hartmann DL (2009) Understanding the importance of microphysics and macrophysics for warm rain marine low clouds. Part II: heuristic models and rain formation. J Atmos Sci 66:2973-2990 